\title{
Animal models of restricted repetitive behavior in autism
}

\author{
Mark H. Lewis ${ }^{a, b, c,}{ }^{*}$, Yoko Tanimura ${ }^{a, b}$, Linda W. Lee ${ }^{a, c}$, and James W. Bodfish ${ }^{d}$ \\ aMcKnight Brain Institute and Department of Psychiatry, University of Florida, Gainesville, FL, \\ USA \\ bBehavioral Neuroscience Program, Department of Psychology, University of Florida, Gainesville, \\ FL, USA \\ 'Department of Neuroscience, University of Florida, Gainesville, FL, USA \\ dDepartment of Psychiatry, University of North Carolina at Chapel Hill, Chapel Hill, NC, USA
}

\begin{abstract}
Restricted, repetitive behavior, along with deficits in social reciprocity and communication, is diagnostic of autism. Animal models relevant to this domain generally fall into three classes: repetitive behavior associated with targeted insults to the CNS; repetitive behavior induced by pharmacological agents; and repetitive behavior associated with restricted environments and experience. The extant literature provides potential models of the repetitive behavioral phenotype in autism rather than attempts to model the etiology or pathophysiology of restricted, repetitive behavior, as these are poorly understood. This review focuses on our work with deer mice which exhibit repetitive behaviors associated with environmental restriction. Repetitive behaviors are the most common category of abnormal behavior observed in confined animals and larger, more complex environments substantially reduce the development and expression of such behavior. Studies with this model, including environmental enrichment effects, suggest alterations in cortical-basal ganglia circuitry in the development and expression of repetitive behavior. Considerably more work needs to be done in this area, particularly in modeling the development of aberrant repetitive behavior. As mutant mouse models continue to proliferate, there should be a number of promising genetic models to pursue.
\end{abstract}

\section{Keywords}

Stereotypy; Deer mice; Environmental enrichment; Basal ganglia; Repetitive behavior

\section{Introduction}

\subsection{Restricted, repetitive behavior in autism}

Restricted, repetitive behavior is one of three behavioral domains, which concurrent with deficits in social interaction and communication, is required for the diagnosis of autism (ICD-10, World Health Organization, 1990; DSM-IV, American Psychiatric Association, 1994). Despite the clinical significance of this class of behavior, the literature devoted to the study of this repetitive behavior in autism is relatively small in comparison with the extensive literature on social and communication deficits [40].

\footnotetext{
(C) 2006 Elsevier B.V. All rights reserved.

*Corresponding author at: 100 S. Newell Dr., P.O. Box 100256, Gainesville, FL 32610, USA. Tel.: +1 3522940415 ; fax: +1 352294 0425., mlewis@psychiatry.ufl.edu (M.H. Lewis).
} 
Repetitive behavior refers to the broad class of behaviors linked by repetition, rigidity, and invariance. In autism these include stereotyped motor movements, repetitive manipulation of objects, repetitive self-injurious behavior, specific object attachments, compulsions, rituals and routines, an "anxiously obsessive desire for sameness" [32], repetitive use of language, and narrow and circumscribed interests. This broad range of behavior has been conceptualized as two clusters: "lower-order" motor actions (stereotyped movements, repetitive manipulation of objects and repetitive forms of self-injurious behavior) that are characterized by repetition of movement, and more complex or "higher-order" behaviors (compulsions, rituals, insistence on sameness, and circumscribed interests) that have a distinct cognitive component. The latter behaviors are characterized by an adherence to some rule or mental set (e.g., needing to have things "just so") [40,64,80]. Indeed, factor analyses of items from the Autism Diagnostic Interview-Revised (ADI-R) [10,73] have yielded two factors (repetitive sensory motor behavior and resistance to change) supporting this categorization. As autism is characterized by the co-occurrence of "lower-order" and "higher-order" repetitive behaviors [4], it is important that relevant animal models include attempts to model both motor and cognitive features of repetitive behaviors.

\subsection{Modeling restricted, repetitive behavior in animals}

Animal models relevant to restricted, repetitive behavior in autism generally fall into three classes: repetitive behavior associated with targeted insults to the CNS; repetitive behavior induced by pharmacological agents; and repetitive behavior associated with restricted environments and experience. These models have generally focused on stereotyped motor behaviors which, in animals, are easier to model than, for example, rituals or insistence on sameness. Nevertheless, some animal work, which we will review, has addressed the domain of cognitive rigidity or resistance to change characteristic of "sameness" behaviors.

The animal studies that we will review largely reflect studies modeling the repetitive behavioral phenotype in autism and are not models of etiology or pathophysiology. This is consistent with our limited understanding of the etiology and pathophysiology of these behaviors in autism. In addition, little work has used relevant models to identify novel biological treatments, although our work and the work of others point to the potential importance of early experiential interventions. In addition to highlighting the role of early experience, we will also review work relevant to resistance to change in animals and highlight animal studies relevant to the critical issue of the development of repetitive behavior.

1.2.1. CNS insult and repetitive behavior in animals-The advent of gene targeting technologies has given rise to the generation of mutant mouse models of various neurodevelopmental disorders. In select cases, the behavioral aberrations characteristic of these genetic models also include specific forms of repetitive behavior. For example, mutations in the methyl-CpG binding protein 2 (MECP2) gene are responsible for the majority of cases of Rett syndrome, one of the pervasive developmental disorders. Mice expressing truncated $\mathrm{MeCP} 2$ protein exhibit repetitive forelimb movements resembling the distinctive hand stereotypies (e.g., hand-wringing, waving, and clapping) observed in Rett syndrome patients $[48,70]$.

The gabrb3 homozygous knockout mouse also shows stereotyped behavior such as intense circling or "tail-chasing" which may continue for hours $[11,25]$. The GABRB3 gene, which codes for the $\beta 3$ subunit of the $\mathrm{GABA}_{\mathrm{A}}$ receptor, lies within the q11-13 region of chromosome 15. In addition to being implicated in autism, deletions or mutations of this region are associated with two human genetic disorders, Prader-Willi syndrome and Angelman syndrome depending on parental contribution. Compulsive behaviors are a 
particularly salient feature of the behavioral phenotype of Prader-Willi syndrome [12]. Ts65Dn mice are segmentally trisomic for the distal portion of mouse chromosome 16, the region containing murine orthologs to human chromosome 21, and provide a model for Down syndrome. The behavioral repertoire of Ts65Dn mice includes repetitive jumping and cage-top twirling. Repetitive motor behaviors, in addition to being diagnostic for autism, are also frequently observed in individuals with Down syndrome [78].

Compulsive grooming leading to hair removal and self-inflicted wounds has been identified as a major behavioral phenotype of the Hoxb8 homozygous mutant mouse [21]. These mice spent almost twice the time self-grooming as wild-type mice and excessively groomed or barbered control cagemates. Interestingly, high levels of expression of Hoxb8 were observed in brain regions known to comprise circuitry mediating obsessive compulsive disorder (OCD) symptoms in patients. This model is particularly relevant to OC spectrum problems such as trichotillomania as well as self-injurious behaviors observed in individuals with autism.

Rather than targeting the major candidate genes or loci thought to be associated with autism, other animal models have examined the role of prenatal risk factors in the etiology of autism. Some models have been generated based on the observation that prenatal exposure to teratogenic agents increases the risk of autism. For example, exposure to valproic acid (VPA), an antiepileptic drug, on embryonic day 12.5 in rats not only produces neuroanatomical abnormalities similar to those reported in autistic individuals but also longterm disturbances in postnatal behavior including increased time spent engaged in stereotypic activity $[27,63,67]$. The stereotypies expressed by the VPA-treated rats are sensitive to environmental perturbations such that housing in an enriched environment results in their attenuation [68]. The VPA induced repetitive behaviors reported in this study represent small movements in the same location in an automated activity monitor. Although such methods allow for high throughput testing, detailed information on the form and temporal structure of the repetitive behavior is often lacking.

The pathogenesis of autism has also been linked to viral infection and lesion-induced damage during early development. In support of this putative association, intracerebral inoculation of newborn rats with Borna disease virus (BDV) induces neuroanatomical and neurochemical deficits similar to those seen in autism. The resulting phenotype of the BDV rat recapitulates many of the behavioral impairments, including stereotypies, commonly observed in autism spectrum disorders [26]. In non-human primates, early damage to amygdala, hippocampal formation and adjacent temporal cortex resulted in a number of behavioral abnormalities including stereotypies [1]. Again, the stereotypies associated with these models are not well described in terms of topography, intensity, or temporal structure.

1.2.2. Drug-induced repetitive behavior-Much of what has been learned about the neurobiological basis of repetitive motor behaviors comes from studies of drug-induced stereotyped behavior. For example, early experiments established the importance of the basal ganglia in the mediation of repetitive behaviors by showing that dopamine or a dopamine agonist (e.g., apomorphine) injected into the corpus striatum induced stereotyped behavior in rats (e.g. [13]). Intrastriatal administration of the glutamate receptor ligand, NMDA, also induces stereotyped behavior that is often indistinguishable from dopamine agonist-induced stereotypy. Such stereotypy can be attenuated by intrastriatal administration of the NMDA receptor antagonist CPP [33]. Notably, glutamatergic induction of stereotypic behavior is not restricted to NMDA-sensitive glutamate receptors, but can also be influenced through modulation of other types of glutamate receptors in the dorsal striatum [43]. 
Intracortical manipulations enhancing the activity of excitatory cortico-striatal projections exacerbate the expression of stereotypy. For instance, administration of either the $\mathrm{D}_{2}$ antagonist sulpiride or the GABA antagonist bicuculline into the frontal cortex enhances the motor stimulatory effects of amphetamine [35,38]. Conversely, amphetamine-induced stereotypy can be attenuated via intracortical infusion of DA or GABAergic agonists [34]. It is thought that midbrain dopaminergic projection neurons regulate the excitability of these corticofugal efferents through activation of GABAergic cortical interneurons, as well as through direct interaction with cortical pyramidal neurons.

Experiments in which the expression of drug-induced stereo-typy was shown to be sensitive to manipulations in the sub-stantia nigra pars reticulata ( $\mathrm{SNpr}$ ) of the direct pathway and the sub-thalamic nucleus (STN) of the indirect pathway also support the hypothesized role of these pathways in repetitive behaviors. Specifically, intranigral GABA agonist administration induces intense stereotypy in rats [66], and administration of a serotonergic (5- $\mathrm{HT}_{2}$ ) antagonist into the STN reduces stereotypy. These manipulations are expected to have altered either directly (intranigral GABA agonist administration) or indirectly (intraSTN $5 \mathrm{HT}_{2}$ antagonist administration) inhibitory GABAergic tone over thalamocortical relay neurons [6] such that manipulations disinhibiting thalamocortical projections induced stereotypy, whereas stereotypy was attenuated by manipulations increasing inhibitory tone in the thalamus [3]. Similarly, direct injections of opiate agonists into the substantia nigra produce intense stereotypies in rats [28], presumably due to disinhibition of nigrostriatal dopaminergic projections, as this manipulation has been shown to elevate striatal dopamine release in mice [87].

1.2.3. Environmental restriction and repetitive behavior-Abnormal repetitive behaviors are commonly displayed in animals housed in zoo, farm, and laboratory environments [44], as well as animals subjected to early social deprivation [23]. Indeed, repetitive behaviors are the most common category of abnormal behavior observed in confined animals [88]. For example, pacing and route-tracing in birds [15,16,29,46], shamchewing and bar-mouthing in pigs [5,62]; crib-biting and head-shaking in horses [2,18,47]; vertical-jumping and backward somersaulting in deer mice [72]; body-rocking and tailbiting in rhesus monkeys [42,75]; pacing and over-grooming in prosimians [74]; and headtwirling in minks [45] are but some examples of aberrant repetitive behaviors observed in animals maintained in confinement. Animal models focused on the sequelae of experiential restriction are relevant to autism given that the early occurrence of social, communicative and adaptive behavior deficits in very young children with autism likely markedly attenuate experience-dependent behavioral and brain development. Of interest is the fact that repetitive motor behavior appears to be an invariant consequence of experiential deprivation or restriction of all species tested.

Although environmentally induced repetitive behaviors share some similarities with druginduced stereotypies, they can be dissociated. For example, in our own studies, neither systemically or intrastriatally administered apomorphine increased cage related stereotypies in deer mice, although other repetitive behaviors (e.g., stereotyped sniffing) were observed [56,59]. These results were also consistent with work done showing that apomorphine did not affect spontaneous stereotypies in bank voles, and nor did the NDMA antagonist MK-801 [82,83].

1.2.4. Resistance to change and repetitive motor behavior-Complex or higherorder repetitive behavior (rituals, insistence on sameness, restricted interests) in individuals with autism reflects a cognitive rigidity or inflexible adherence to routines and rituals. Recent work has shown that the degree of restricted, repetitive behavior in individuals with autism correlates positively with deficits on executive function tasks that index cognitive 
flexibility [41]. Importantly, this association was observed after controlling for level of cognitive function. Cognitive flexibility, or resistance to change, can be assessed in animals using a variety of tasks that range in complexity from response extinction to reversal learning to intra- and extra-dimensional set shifting (e.g. [8]). Recent work conducted with several different species has demonstrated that motor stereotypies are inversely correlated with measures of cognitive flexibility. For example, in bank voles and bears extinction learning was significantly inversely correlated with the amount of stereotypy [15,84]. Similarly, Orange wing Amazon parrots were assessed for stereotypy and performance on a variation of a gambling task which indexed the tendency to repeat responses or perseverate. Animals with higher stereotypy scores exhibited greater sequential dependency in their responses on this task [16]. In our own work, we have examined the performance of deer mice in a procedural learning task that involved learning to turn down the right or left arm of a T-maze for reinforcement. Following acquisition the reinforced arm was reversed. Our results indicate that high levels of stereotypy in deer mice were associated with deficits in reversal learning in the T-maze. The relationship between cognitive rigidity (deficits in set shifting, extinction, and reversal learning) and motor stereotypy is perhaps not surprising given the common mediation by cortical-basal ganglia pathways. Thus, alterations in this circuitry could well impair the ability to inhibit pre-potent responding, the ability to orient to novel events and the ability to generate flexible patterns of behavior.

\subsection{Environmental enrichment and repetitive behavior}

If environmental restriction induces repetitive behavior, environmental complexity should ameliorate or prevent it. Indeed, providing animals more complex environments appears to be an effective means of attenuating repetitive behavior [5,46,71,72]. In our own work, we have shown that deer mice reared in larger, more complex environments exhibit substantially less stereo-typy than do deer mice reared in standard laboratory cages [54,55,72,73,75]. Deer mice (Peromyscus maniculatus) exhibit repetitive behaviors (i.e., hindlimb jumping, backward somersaulting) that occur at a high rate, persist across the life of the animal and appear relatively early in development. These behaviors are associated with standard laboratory housing and do not require isolation housing, specific cues or contexts, or a pharmacological agent for induction. These features plus considerable heterogeneity in individual levels of expression, modulation by early experience, mediation by cortical-basal ganglia circuitry, and association with cognitive rigidity (see later section) make this model an appealing model of restricted, repetitive behavior in autism.

The efficacy of environmental complexity in attenuating or preventing aberrant repetitive behavior leads to the question of neurobiological mechanisms and potential translation to clinical intervention. Environmental enrichment has been reported to be associated with myriad CNS effects including dendritic branching, spine density, synaptogenesis, angiogenesis, gliogenesis (e.g. [9,20]), gene expression, apoptosis, and neurogenesis $[37,60,81,89]$. Moreover, exposing animals to more complex environments has also been shown to attenuate or reverse the sequelae of such CNS insults as seizures, ischemia, infarct, cortical lesion, and traumatic brain injury [22,30,31,39,89], and to be protective with regard to the sequelae of genetic mutations. Enrichment studies can assist in identifying the molecular targets associated with experience-dependent plasticity and prevention/attenuation of repetitive behaviors. Such information may well be useful in the development of novel pharmacological agents targeted for the treatment of abnormal repetitive behaviors in autism.

\section{Methods}

A critical question for our group has been which of the large number of brain changes associated with increased environmental complexity are operative in the prevention of 
abnormal repetitive behavior. We are not aware of any work, save our own, identifying neurobiological mechanisms that mediate the ameliorative or preventative effects of environmental complexity on repetitive behavior. In three related studies $[76,77,79]$, we examined the enrichment-related changes in neuronal structure and function and related these to stereotypic behavior in our animals. In all the studies, deer mice were reared in enriched or standard cages for 60 days post-weaning, before being tested and classified as 'low stereotypy' or 'high stereotypy'. This testing paradigm thus yielded four distinct groups: enriched high stereotypy, enriched low stereotypy, standard cage high stereotypy, and standard cage low stereotypy. This four-group design allowed us to avoid confounding behavioral outcome (high stereotypy/low stereotypy) with housing condition (standard/ enriched).

In subsequent studies using deer mice housed in standard laboratory cages, we examined directly the role of cortical-basal ganglia circuitry on the expression of repetitive behavior. This was done using intrastriatal administration of select pharmacological agents that blocked cortico-striatal glutamatergic afferents and nigrostriatal dopamine projections. We also examined the balance between direct and indirect basal ganglia pathways using radioimmunoassays to quantify the activity of neuropeptides (dynorphin and enkephalin, respectively) that serve as markers of these pathways.

\section{Results}

\subsection{Neuronal metabolic activity}

Our initial studies assessed whether environmental enrichment-related effects on the development of stereotyped behavior in deer mice were associated with alterations in neuronal metabolic activity [79]. Neuronal activity was assessed using cytochrome oxidase (CO) histochemistry, an index of oxidative energy metabolism. CO indexes long-term changes in neuronal functional activity and has been shown to correlate with indices of activity-dependent plasticity $[53,86]$. In motor cortex, striatum, nucleus accumbens, thalamus, and hippocampus, our findings revealed a clear and striking environment by behavior interaction. The low stereotypy, enriched housed animals had relatively high CO activity in all of these brain regions. High stereotypy animals had relatively low CO levels, regardless of their housing type. So too did the standard housed mice which did not develop stereotypies; and these three groups did not significantly differ.

\subsection{Dendritic morphology}

In a subsequent study, we evaluated whether the environmental enrichment-related effects on the development of stereotyped behavior were associated with alterations in dendritic morphology [77]. Dendritic morphology was assessed in layer V pyramidal neurons of the motor cortex, medium spiny neurons of the dorsolateral striatum and granule cells of the dentate gyrus using Golgi-Cox histochemistry [17]. These brain regions were selected based on our $\mathrm{CO}$ findings suggesting the importance of cortical-basal ganglia circuitry and relative lack of importance of limbic areas. Again, we found an environment by behavior interaction, with the low stereotypy, enriched housed animals differing from each of the three other groups, which in turn were statistically indistinguishable from each other. The enriched low stereotypy mice exhibited significantly higher dendritic spine densities in the motor cortex and striatum, compared with the other groups. Importantly no group differences in hippocampal spine density were found.

\subsection{Neurotrophic factors}

As neurotrophins promote neuron survival and growth, and play an important role in usedependent plasticity, we assessed their relationship to the prevention or attenuation of the 
development of stereotypy [76]. Levels of brain-derived neurotrophic factor (BDNF) and nerve growth factor (NGF) were assessed in motor cortex, striatum, and hippocampus. There were no differences in either NGF or BDNF in either the motor cortex or the hippocampus of enriched and standard cage mice. As we predicted, however, enriched, low stereotypy mice exhibited significantly more BDNF (but not NGF) in the striatum than the enriched high stereotypy and standard cage mice.

\subsection{Basal ganglia mediated learning and cognitive flexibility}

As indicated in a preceding section, we have shown that deer mice exhibiting high levels of repetitive motor behavior exhibit deficits in reversal learning. We have also observed poorer procedural learning in a group of high stereotypy animals consistent with alterations in basal ganglia function (unpublished observations). We hypothesized that environmental enrichment associated with the prevention of stereotypy would also be associated with better performance on both procedural learning and reversal learning tasks. This hypothesis was supported by our preliminary findings.

\subsection{Summary}

Taken together, these results suggest three general conclusions. First, enrichment-related brain differences were observed only in mice that "benefited" from enrichment as defined by prevention/attenuation of stereotypy. Second, enrichment effects were regionally selective for motor cortex and basal ganglia. Finally, enrichment effects on repetitive motor behaviors were associated with improved performance on procedural and reversal learning tasks. These results point to the importance of cortical-basal ganglia circuitry in the development and expression of repetitive behavior.

\subsection{Repetitive behavior and cortical-basal ganglia circuitry}

Our environmental complexity findings suggest alterations in cortical-basal ganglia circuitry in the development of repetitive behavior. The view that spontaneous and persistent repetitive behavior is linked to dysfunction of the neural circuits that transmit information between the cortex and basal ganglia is supported by several lines of evidence from studies in autism. For example, in Fragile $\mathrm{X}$ syndrome, caudate volume has been significantly correlated with stereotypies [61]. In MRI studies of autism, caudate volume was associated with repetitive behavior $[69,24]$, and frontal white matter and caudate volumes were reduced in stereotypy subjects who had no other known developmental or neurological disorder [36].

We postulate that stereotypic behavior is expressed as a consequence of abnormal facilitation of selected motor programs due to imbalanced activity between this direct (or striatonigral) pathway and the indirect (or striatopallidal) basal ganglia pathway (see Fig. 1).

In support of such a model, we have shown that stereotypy in deer mice was attenuated selectively via intrastriatal administration of either the D1 dopamine receptor selective antagonist SCH23390 or the NMDA receptor-selective glutamate antagonist MK-801 [58]. Importantly, observational data indicated no significant drug-related changes in nonstereotypic motor behavior. These results show that interruption of cortical projections to striatum by MK-801 or dopaminergic projections to striatum from substantia nigra can selectively reduce spontaneous stereotypy via alterations in the direct pathway.

Furthermore, we hypothesized that repetitive behavior in deer mice would be associated with an imbalance in the activity of the direct and indirect pathways of the basal ganglia, favoring overactivity of the direct pathway. We measured the concentrations of the striatal neuropeptides dynorphin and enkephalin in dorsolateral striatum in high and low stereotypy deer mice reared in standard cages [57]. These neuropeptides are expressed in striatonigral 
and striatopallidal medium spiny GABA neurons, respectively. Our results indicated significantly decreased leu-enkephalin content and significantly increased [dynorphin]/ [enkephalin] content ratios in the high-stereotypy mice relative to low-stereotypy mice. Moreover, we saw a significant negative correlation between striatal enkephalin content (indexing indirect pathway activity) and frequency of stereo-typy $(r=-0.40)$, as well as a significant positive correlation between the dynorphin/enkephalin content ratio and frequency of stereotypy $(r=0.42)$ in these mice. These data are consistent with our hypothesis that spontaneous stereotypic behavior is a consequence of relative hyperactivity along cortico-basal ganglia-cortical feedback circuits involving the direct (facilitative) pathway, but suggest that primary perturbations to the indirect (inhibitory) pathway give rise to such imbalanced activity.

\section{Discussion}

\subsection{Development of repetitive behavior: neurobiological mechanisms}

As Symons et al. [72] have pointed out in their recent review, very little is known about the development of repetitive behaviors in children at risk for neurodevelopmental disorders such as autism. This lack of knowledge seriously impairs the ability of clinicians to design efficacious early intervention and prevention strategies. Appropriate animal models could provide a wealth of information about the developmental characteristics of such behavior. For example, such models could help identify the neurobiological mechanisms that mediate the transition from repetitive behavior common to typically developing children [14] to the developmentally inappropriate, persistent, fixed, and habitual repetitive behaviors characteristic of autism. Animal models used by several labs appear to be highly relevant to this developmental question.

For example, there is now considerable evidence that the development of repetitive behavior (e.g., stereotypies, dyskinesia) following repeated drug exposure is associated with a preferentially increased immediate early gene (IEG) expression in striatal striosomes (e.g. [65]). Indeed, this increased IEG expression (c-Fos, FosB) in striosomes following drugs like cocaine and amphetamine reliably predicts motor stereotypies [7]. These plasticity related changes also appear to be progressively more evident in the dorsal aspect of the striatum with increased drug exposure. In addition, the shift in metabolic activity to striosomes appears to be due largely to a decline in matrix activity. This shift from matrix to striosomes could reflect a shift toward more motivationally driven behavior with a consequent narrowing of focus and escalation of repetition [19].

There has, as yet, been no examination of similar dynamical changes occurring coincident with the development and consolidation of non-drug induced stereotypies. Nonetheless, the persistence of spontaneous stereotypies is presumably due to changes in gene expression as well. For these longer-term changes associated with chronic exposure to environmental conditions, transcription factors are also likely altered in brain. As Nestler has suggested [49,50], $\Delta$ FosB may be a good candidate for examining long-term experience-dependent plasticity. $\triangle$ FosB is a member of the Fos family of transcription factors (c-Fos, FosB, FRA1, FRA2) that heterodimerize with Jun proteins to form active AP-1 transcription factors that bind to AP-1 sites expressed in the promoters of certain genes. Importantly, whereas some Fos and Jun family proteins are induced very rapidly, albeit transiently, isoforms of $\Delta$ FosB have been shown to be induced after chronic exposure to different stimuli (e.g., stress, drugs of abuse, chronic wheel running) and to persist in brain for much longer periods of time. For example, virtually all drugs of abuse result in $\triangle$ FosB induction. Voluntary wheel running induces $\triangle \mathrm{FosB}$ in striatal dynorphin containing neurons and LDOPA induced dyskinesias are associated with increased $\triangle$ FosB expression, again in neurons of the direct pathway. Interestingly, transgenic animals that selectively over-express 
the transcription factor $\Delta$ FosB in striatonigral projection neurons exhibit excessive wheel running, whereas wheel running is significantly inhibited in animals that overexpress the gene in striatopallidal projection (indirect pathway) neurons [85]. These studies support the hypothesis that repetitive behaviors are expressed as a result of imbalanced activity along the direct and indirect pathways of the basal ganglia and that this imbalance is characterized by a relative increase in striatonigral tone. Thus, $\Delta$ FosB isoforms may play a very important role in mediating long-term changes in gene expression that mediate repetitive behavior [50].

Advances in the neural basis of birdsong appear to have much to contribute to our understanding of the transition in behavior from variability to stereotypy. For example, oscine songbirds imitate older members of their species and progress through stages where song production starts out highly variable but becomes increasingly stereotyped. Recent studies have determined that lesions of the anterior forebrain pathway (AFP; homologous to basal ganglia thalamo-cortical loops) in juvenile zebra finches markedly disrupt song development but have few effects in adult birds. Specifically, inactivation of an AFP nucleus (lateral magnocellular nucleus of the nidopallium or LMAN) results in a dramatic loss of variability in song typical of juveniles [51]. Instead song production is highly stereotyped, similar to that observed in adults. Models such as these may be of great help in understanding the mechanism by which variable behavior becomes stereotyped.

\section{Summary}

Our understanding of abnormal repetitive behavior in animals has come largely from models involving pharmacological induction of repetitive behavior and from models of environmental restriction or deprivation. Pharmacological studies have provided much of what we know about the relevant neuronal circuitry and a number of the drugs (e.g., cocaine, amphetamine) used to induce repetitive behavior in animals also can induce repetitive behavior in humans. Models of insult to the CNS (e.g., genetic mutations, viral exposure, lesions) associated with repetitive behaviors are particularly appealing as they promise clues to etiology and pathophysiology. As yet, there are only a limited number of these models and the accompanying repetitive behaviors have often not been well characterized.

Nonetheless, as mutant mouse models continue to proliferate, there should be a number of promising models to pursue.

A very large literature exists on repetitive behavior and environmental restriction or social deprivation. Many species are represented in this literature [42] and the effects of early social deprivation have, unfortunately, been demonstrated to extend to humans. Models of restricted, repetitive behavior induced by environmental restriction may, on the surface, seem of limited relevance to autism. Nonetheless, individuals with autism suffer from deficits in a number of domains of functioning including social, emotional, motor, and cognitive. Thus, such children may be thought of as functionally environmentally restricted. Marked deficits in exploration [52] would support such a view. The efficacy of environmental enrichment in preventing repetitive behavior may have important clinical implications. The development of effective strategies for bringing children with autism into more functional or meaningful contact with their environment would seem a promising strategy. In addition, as we identify enrichment-induced changes in specific molecular processes, specific proteins can be targeted for pharmacological or biological intervention.

Work with animal models of repetitive behavior has pointed to the importance of corticalbasal ganglia circuitry in mediating the expression of these behaviors. More detailed work with multiple models needs to be done to determine what specific loops map onto what specific repetitive behaviors. This more refined understanding of pathophysiology should, in 
turn, lead to better treatment options. Considerably more work needs to be done in the area of modeling the development of aberrant repetitive behavior. Ultimately, this work holds the greatest promise for generating research findings that can be used for early intervention and treatment.

\section{References}

1. Bachevalier J, Loveland KA. The orbitofrontal-amygdala circuit and self-regulation of socialemotional behavior in autism. Neurosci Biobehav Rev. 2006; 30(1):97-117. [PubMed: 16157377]

2. Bachmann I, Audige L, Stauffacher M. Risk factors associated with behavioural disorders of cribbiting, weaving and box-walking in Swiss horses. Equine Vet J. 2003; 35(2):158-63. [PubMed: 12638792]

3. Barwick VS, Jones DH, Richter JT, Hicks PB, Young KA. Subthalamic nucleus microinjections of 5-HT2 receptor antagonists suppress stereotypy in rats. Neuroreport. 2000; 11(2):267-70. [PubMed: 10674468]

4. Bodfish JW, Symons FJ, Parker DE, Lewis MH. Varieties of repetitive behavior in autism: comparisons to mental retardation. J Autism Dev Disord. 2000; 30(3):237-43. [PubMed: 11055459]

5. Bolhuis JE, Schouten WG, de Leeuw JA, Schrama JW, Wiegant VM. Individual coping characteristics, rearing conditions and behavioural flexibility in pigs. Behav Brain Res. 2004; 152(2):351-60. [PubMed: 15196803]

6. Brunken WJ, Jin XT. A role for $5 \mathrm{HT} 3$ receptors in visual processing in the mammalian retina. Vis Neurosci. 1993; 10(3):511-22. [PubMed: 8494802]

7. Canales JJ, Graybiel AM. Patterns of gene expression and behavior induced by chronic dopamine treatments. Ann Neurol. 2000; 47(4 Suppl 1):S53-9. [PubMed: 10762132]

8. Colacicco G, Welzl H, Lipp HP, Wurbel H. Attentional set-shifting in mice: modification of a rat paradigm, and evidence for strain-dependent variation. Behav Brain Res. 2002; 132(1):95-102. [PubMed: 11853862]

9. Comery TA, Shah R, Greenough WT. Differential rearing alters spine density on medium-sized spiny neurons in the rat corpus striatum: evidence for association of morphological plasticity with early response gene expression. Neurobiol Learn Mem. 1995; 63(3):217-9. [PubMed: 7670834]

10. Cuccaro ML, Shao Y, Grubber J, Slifer M, Wolpert CM, Donnelly SL, et al. Factor analysis of restricted and repetitive behaviors in autism using the Autism Diagnostic Interview-R. Child Psychiatry Hum Dev. 2003; 34(1):3-17. [PubMed: 14518620]

11. DeLorey TM, Handforth A, Anagnostaras SG, Homanics GE, Minassian BA, Asatourian A, et al. Mice lacking the beta3 subunit of the GABAA receptor have the epilepsy phenotype and many of the behavioral characteristics of Angelman syndrome. J Neurosci. 1998; 18(20):8505-14. [PubMed: 9763493]

12. Dykens EM. Maladaptive and compulsive behavior in Prader-Willi syndrome: new insights from older adults. Am J Ment Retard. 2004; 109(2):142-53. [PubMed: 15000675]

13. Ernst AM, Smelik PG. Site of action of dopamine and apomorphine on compulsive gnawing behaviour in rats. Experientia. 1966; 22(12):837-8. [PubMed: 5973232]

14. Evans DW, Leckman JF, Carter A, Reznick JS, Henshaw D, King RA, et al. Ritual, habit, and perfectionism: the prevalence and development of compulsive-like behavior in normal young children. Child Dev. 1997; 68(1):58-68. [PubMed: 9084125]

15. Garner JP, Mason GJ. Evidence for a relationship between cage stereotypies and behavioural disinhibition in laboratory rodents. Behav Brain Res. 2002; 136(1):83-92. [PubMed: 12385793]

16. Garner JP, Meehan CL, Mench JA. Stereotypies in caged parrots, schizophrenia and autism: evidence for a common mechanism. Behav Brain Res. 2003; 145(1/2):125-34. [PubMed: 14529811]

17. Gibb R, Kolb B. A method for vibratome sectioning of Golgi-Cox stained whole rat brain. J Neurosci Meth. 1998; 79(1):1-4.

18. Goodwin D, Davidson HP, Harris P. Foraging enrichment for stabled horses: effects on behaviour and selection. Equine Vet J. 2002; 34(7):686-91. [PubMed: 12455839] 
19. Graybiel AM, Canales JJ, Capper-Loup C. Levodopa-induced dyskinesias and dopaminedependent stereotypies: a new hypothesis. Trends Neurosci. 2000; 23(10 Suppl):S71-7. [PubMed: 11052223]

20. Greenough WT, Hwang HM, Gorman C. Evidence for active synapse formation or altered postsynaptic metabolism in visual cortex of rats reared in complex environments. Proc Natl Acad Sci USA. 1985; 82(13):4549-52. [PubMed: 3859876]

21. Greer JM, Capecchi MR. Hoxb8 is required for normal grooming behavior in mice. Neuron. 2002; 33(1):23-34. [PubMed: 11779477]

22. Hamm RJ, Temple MD, O’Dell DM, Pike BR, Lyeth BG. Exposure to environmental complexity promotes recovery of cognitive function after traumatic brain injury. J Neurotrauma. 1996; 13(1): 41-7. [PubMed: 8714862]

23. Harlow HF, Dodsworth RO, Harlow MK. Total social isolation in monkeys. Proc Natl Acad Sci USA. 1965; 54(1):90-7. [PubMed: 4955132]

24. Hollander E, Anagnostou E, Chaplin W, Esposito W, Haznedar M, Licalzi E, et al. Striatal volume on magnetic resonance imaging and repetitive behaviors in autism. Biol Psychiat. 2005; 58:22632. [PubMed: 15939406]

25. Homanics GE, DeLorey TM, Firestone LL, Quinlan JJ, Handforth A, Harrison NL, et al. Mice devoid of gamma-aminobutyrate type A receptor beta3 subunit have epilepsy, cleft palate, and hypersensitive behavior. Proc Natl Acad Sci USA. 1997; 94(8):4143-8. [PubMed: 9108119]

26. Hornig M, Weissenbock H, Horscroft N, Lipkin WI. An infection-based model of neurodevelopmental damage. Proc Natl Acad Sci USA. 1999; 96(21):12102-7. [PubMed: 10518583]

27. Ingram JL, Peckham SM, Tisdale B, Rodier PM. Prenatal exposure of rats to valproic acid reproduces the cerebellar anomalies associated with autism. Neurotoxicol Teratol. 2000; 22(3): 319-24. [PubMed: 10840175]

28. Iwamoto ET, Way EL. Circling behavior and stereotypy induced by intranigral opiate microinjections. J Pharmacol Exp Ther. 1977; 203(2):347-59. [PubMed: 561844]

29. Jenkins JR. Feather picking and self-mutilation in psittacine birds. Vet Clin North Am Exot Anim Pract. 2001; 4(3):651-67. [PubMed: 11601106]

30. Johansson BB. Functional outcome in rats transferred to an enriched environment 15 days after focal brain ischemia. Stroke. 1996; 27(2):324-6. [PubMed: 8571431]

31. Johansson BB, Ohlsson AL. Environment, social interaction, and physical activity as determinants of functional outcome after cerebral infarction in the rat. Exp Neurol. 1996; 139(2):322-7. [PubMed: 8654535]

32. Kanner L. Autistic disturbances of affected content. Nervous Child. 1943; 2:3-20.

33. Karler R, Bedingfield JB, Thai DK, Calder LD. The role of the frontal cortex in the mouse in behavioral sensitization to amphetamine. Brain Res. 1997; 757(2):228-35. [PubMed: 9200751]

34. Karler R, Calder LD, Thai DK, Bedingfield JB. The role of dopamine and GABA in the frontal cortex of mice in modulating a motor-stimulant effect of amphetamine and cocaine. Pharmacol Biochem Behav. 1998; 60(1):237-44. [PubMed: 9610948]

35. Karler R, Calder LD, Thai DK, Bedingfield JB. The role of dopamine in the mouse frontal cortex: a new hypothesis of behavioral sensitization to amphetamine and cocaine. Pharmacol Biochem Behav. 1998; 61(4):435-43. [PubMed: 9802839]

36. Kates WR, Lanham DC, Singer HS. Frontal white matter reductions in healthy males with complex stereotypies. Pediatr Neurol. 2005; 32(2):109-12. [PubMed: 15664770]

37. Kempermann G, Gast D, Gage FH. Neuroplasticity in old age: sustained fivefold induction of hippocampal neurogenesis by long-term environmental enrichment. Ann Neurol. 2002; 52(2):13543. [PubMed: 12210782]

38. Kiyatkin EA, Rebec GV. Modulation of striatal neuronal activity by glutamate and GABA: iontophoresis in awake, unrestrained rats. Brain Res. 1999; 822(1/2):88-106. [PubMed: 10082887]

39. Kolb B, Gibb R. Environmental enrichment and cortical injury: behavioral and anatomical consequences of frontal cortex lesions. Cereb Cortex. 1991; 1(2):189-98. [PubMed: 1822732]

40. Lewis MH, Bodfish JW. Repetitive behavior disorders in autism. Ment Retard Dev Disabil Res Rev. 1998; 4:80-9. 
41. Lopez BR, Lincoln AJ, Ozonoff S, Lai Z. Examining the relationship between executive functions and restricted, repetitive symptoms of autistic disorder. J Autism Dev Disord. 2005; 35(4):445-60. [PubMed: 16134030]

42. Lutz C, Well A, Novak M. Stereotypic and self-injurious behavior in rhesus macaques: a survey and retrospective analysis of environment and early experience. Am J Primatol. 2003; 60(1):1-15. [PubMed: 12766938]

43. Mao L, Wang JQ. Motor stimulation following bilateral injection of the group-I metabotropic glutamate receptor agonist into the dorsal striatum of rats: evidence against dependence on ionotropic glutamate receptors. Psychopharmacology (Berl). 2000; 148(4):367-73. [PubMed: 10928309]

44. Mason GJ. Stereotypies: a critical review. Anim Behav. 1991; 41:1015-37.

45. Mason GJ. Age and context affect the stereotypies of caged mink. Behaviour. 1993; 127:191-229.

46. Meehan CL, Garner JP, Mench JA. Environmental enrichment and development of cage stereotypy in Orange-winged Amazon parrots (Amazona amazonica). Dev Psychobiol. 2004; 44(4):209-18. [PubMed: 15103731]

47. Mills DS, Taylor K. Field study of the efficacy of three types of nose net for the treatment of headshaking in horses. Vet Rec. 2003; 152(2):41-4. [PubMed: 12553579]

48. Moretti P, Bouwknecht JA, Teague R, Paylor R, Zoghbi HY. Abnormalities of social interactions and home-cage behavior in a mouse model of Rett syndrome. Hum Mol Genet. 2005; 14(2):20520. [PubMed: 15548546]

49. Nestler EJ, Barrot M, Self DW. DeltaFosB: a sustained molecular switch for addiction. Proc Natl Acad Sci USA. 2001; 98(20):11042-6. [PubMed: 11572966]

50. Nestler EJ, Kelz MB, Chen J. DeltaFosB: a molecular mediator of long-term neural and behavioral plasticity. Brain Res. 1999; 835(1):10-7. [PubMed: 10448191]

51. Olveczky BP, Andalman AS, Fee MS. Vocal experimentation in the juvenile ongbird requires a basal ganglia circuit. PLoS Biol. 2005; 3(5):e153. [PubMed: 15826219]

52. Pierce K, Courchesne E. Evidence for a cerebellar role in reduced exploration and stereotyped behavior in autism. Biol Psychiatry. 2001; 49(8):655-64. [PubMed: 11313033]

53. Poremba A, Jones D, Gonzalez-Lima F. Classical conditioning modifies cytochrome oxidase activity in the auditory system. Eur J Neurosci. 1998; 10(10):3035-43. [PubMed: 9786198]

54. Powell SB, Newman HA, McDonald TA, Bugenhagen P, Lewis MH. Development of spontaneous stereotyped behavior in deer mice: effects of early and late exposure to a more complex environment. Dev Psychobiol. 2000; 37(2):100-8. [PubMed: 10954835]

55. Powell SB, Newman HA, Pendergast JF, Lewis MH. A rodent model of spontaneous stereotypy: initial characterization of developmental, environmental, and neurobiological factors. Physiol Behav. 1999; 66(2):355-63. [PubMed: 10336165]

56. Presti MF, Gibney BC, Lewis MH. Effects of intrastriatal administration of selective dopaminergic ligands on spontaneous stereotypy in mice. Physiol Behav. 2004; 80(4):433-9. [PubMed: 14741227]

57. Presti MF, Lewis MH. Striatal opioid peptide content in an animal model of spontaneous stereotypic behavior. Behav Brain Res. 2005; 157(2):363-8. [PubMed: 15639187]

58. Presti MF, Mikes HM, Lewis MH. Selective blockade of spontaneous motor stereotypy via intrastriatal pharmacological manipulation. Pharmacol Biochem Behav. 2003; 74(4):833-9. [PubMed: 12667897]

59. Presti MF, Powell SB, Lewis MH. Dissociation between spontaneously emitted and apomorphineinduced stereotypy in Peromyscus maniculatus bairdii. Physiol Behav. 2002; 75(3):347-53. [PubMed: 11897261]

60. Rampon C, Jiang CH, Dong H, Tang YP, Lockhart DJ, Schultz PG, et al. Effects of environmental enrichment on gene expression in the brain. Proc Natl Acad Sci USA. 2000; 97(23):12880-4. [PubMed: 11070096]

61. Reiss AL, Abrams MT, Greenlaw R, Freund L, Denckla MB. Neurodevelopmental effects of the FMR-1 full mutation in humans. Nat Med. 1995; 1:159-67. [PubMed: 7585014] 
62. Rodarte LF, Ducoing A, Galindo F, Romano MC, Valdez RA. The effect of environmental manipulation on behavior, salivary cortisol, and growth of piglets weaned at 14 days of age. J Appl Anim Welf Sci. 2004; 7(3):171-9. [PubMed: 15498724]

63. Rodier PM, Ingram JL, Tisdale B, Croog VJ. Linking etiologies in humans and animal models: studies of autism. Reprod Toxicol. 1997; 11(2/3):417-22. [PubMed: 9100317]

64. Rutter M. Diagnosis and definition of childhood autism. J Autism Child Schizophr. 1978; 8:13961. [PubMed: 670129]

65. Saka E, Goodrich C, Harlan P, Madras BK, Graybiel AM. Repetitive behaviors in monkeys are linked to specific striatal activation patterns. J Neurosci. 2004; 24(34):7557-65. [PubMed: 15329403]

66. Scheel-Kruger J, Arnt J, Braestrup C, Christensen AV, Cools AR, Magelund G. GABA-dopamine interaction in substantia nigra and nucleus accumbens-relevance to behavioral stimulation and stereotyped behavior. Adv Biochem Psychopharmacol. 1978; 19:343-6. [PubMed: 567933]

67. Schneider T, Przewlocki R. Behavioral alterations in rats prenatally exposed to valproic acid: animal model of autism. Neuropsychopharmacology. 2005; 30(1):80-9. [PubMed: 15238991]

68. Schneider T, Turczak J, Przewlocki R. Environmental enrichment reverses behavioral alterations in rats prenatally exposed to valproic acid: issues for a therapeutic approach in autism. Neuropsychopharmacology. 2006; 31(1):36-46. [PubMed: 15920505]

69. Sears LL, Vest C, Mohamed S, Bailey J, Ranson BJ, Piven J. An MRI study of the basal ganglia in autism. Prog Neuropsychopharmacol Biol Psychiat. 1999; 23:613-24.

70. Shahbazian M, Young J, Yuva-Paylor L, Spencer C, Antalffy B, Noebels J, et al. Mice with truncated MeCP2 recapitulate many Rett syndrome features and display hyperacetylation of histone H3. Neuron. 2002; 35(2):243-54. [PubMed: 12160743]

71. Swaisgood RR, White AM, Zhou X, Zhang G, Lindburg DG. How do giant pandas (Ailuropoda melanoleuca) respond to varying properties of enrichments? A comparison of behavioral profiles among five enrichment items. J Comp Psychol. 2005; 119(3):325-34. [PubMed: 16131261]

72. Symons FJ, Sperry LA, Dropik PL, Bodfish JW. The early development of stereotypy and selfinjury: a review of research methods. J Intellect Disabil Res. 2005; 49(Pt 2):144-58. [PubMed: 15634323]

73. Szatmari P, Georgiades S, Bryson S, Zwaigenbaum L, Roberts W, Mahoney W, et al. Investigating the structure of the restricted, repetitive behaviours and interests domain of autism. J Child Psychol Psychiatry. 2006; 73:582-90. [PubMed: 16712635]

74. Tarou LR, Bloomsmith MA, Maple TL. Survey of stereotypic behavior in prosimians. Am J Primatol. 2005; 65(2):181-96. [PubMed: 15706583]

75. Taylor DK, Bass T, Flory GS, Hankenson FC. Use of low-dose chlorpromazine in conjunction with environmental enrichment to eliminate self-injurious behavior in a rhesus macaque (Macaca mulatta). Comp Med. 2005; 55(3):282-8. [PubMed: 16089178]

76. Turner CA, Lewis MH. Environmental enrichment: effects on stereotyped behavior and neurotrophin levels. Physiol Behav. 2003; 80(2/3):259-66. [PubMed: 14637224]

77. Turner CA, Lewis MH, King MA. Environmental enrichment: effects on stereotyped behavior and dendritic morphology. Dev Psychobiol. 2003; 43(1):20-7. [PubMed: 12794775]

78. Turner CA, Presti MF, Newman HA, Bugenhagen P, Crnic L, Lewis MH. Spontaneous stereotypy in an animal model of Down syndrome: Ts65Dn mice. Behav Genet. 2001; 31(4):393-400. [PubMed: 11720125]

79. Turner CA, Yang MC, Lewis MH. Environmental enrichment: effects on stereotyped behavior and regional neuronal metabolic activity. Brain Res. 2002; 938(1/2):15-21. [PubMed: 12031530]

80. Turner M. Repetitive behaviour in autism: a review of psychological research. J Child Psychol Psychiatry. 1999; 40(6):839-49. [PubMed: 10509879]

81. van Praag H, Kempermann G, Gage FH. Running increases cell proliferation and neurogenesis in the adult mouse dentate gyrus. Nat Neurosci. 1999; 2(3):266-70. [PubMed: 10195220]

82. Vandebroek I, Berckmoes V, Odberg FO. Dissociation between MK-801-and captivity-induced stereotypies in bank voles. Psychopharmacology (Berl). 1998; 137(3):205-14. [PubMed: 9682997]

83. Vandebroek I, Odberg FO. Effect of apomorphine on the conflict-induced jumping stereotypy in bank voles. Pharmacol Biochem Behav. 1997; 57(4):863-8. [PubMed: 9259017] 
84. Vickery SS, Mason GJ. Stereotypy and perseverative responding in caged bears: further data and analyses. Appl Anim Behav Sci. 2005; 91:247-60.

85. Werme M, Messer C, Olson L, Gilden L, Thoren P, Nestler EJ, et al. Delta FosB regulates wheel running. J Neurosci. 2002; 22(18):8133-8. [PubMed: 12223567]

86. Wong-Riley M, Anderson B, Liebl W, Huang Z. Neurochemical organization of the macaque striate cortex: correlation of cytochrome oxidase with $\mathrm{Na}+\mathrm{K}+$ ATPase, NADPH-diaphorase, nitric oxide synthase, and $N$-methyl-D-aspartate receptor subunit 1 . Neuroscience. 1998; 83(4): 1025-45. [PubMed: 9502244]

87. Wood PL, Richard JW. Morphine and nigrostriatal function in the rat and mouse: the role of nigral and striatal opiate receptors. Neuropharmacology. 1982; 21(12):1305-10. [PubMed: 6296716]

88. Wurbel H. Ideal homes? Housing effects on rodent brain and behaviour. Trends Neurosci. 2001; 24(4):207-11. [PubMed: 11250003]

89. Young D, Lawlor PA, Leone P, Dragunow M, During MJ. Environmental enrichment inhibits spontaneous apoptosis, prevents seizures and is neuro-protective. Nat Med. 1999; 5(4):448-53. [PubMed: 10202938] 


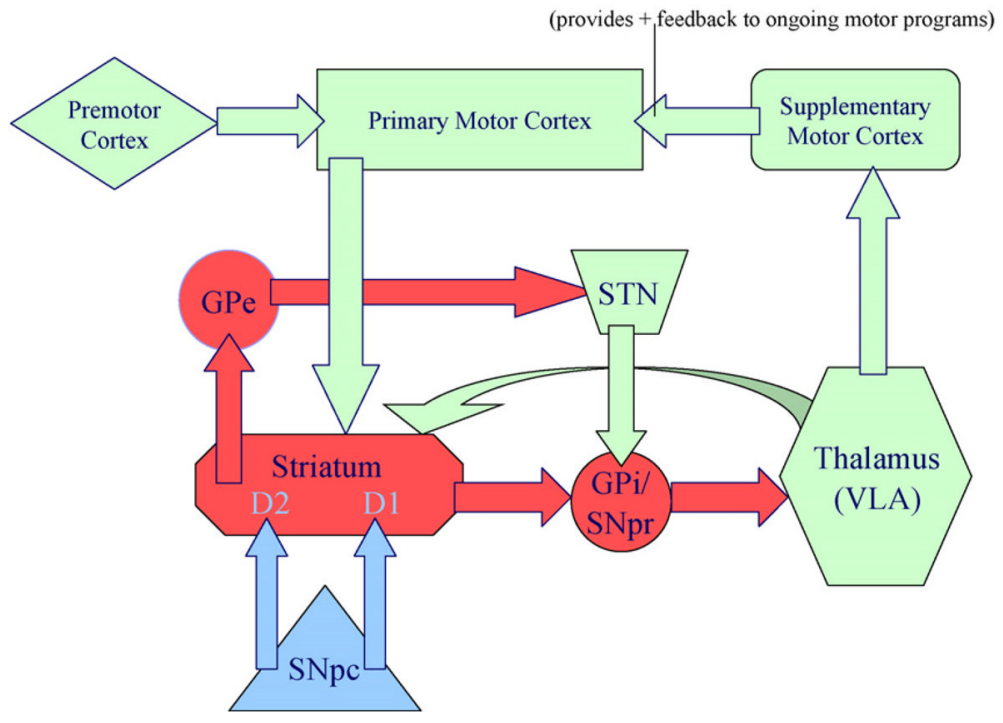

Fig. 1.

Cortical-basal ganglia circuitry. Green indicates projection uses glutamate as a neurotransmitter; red indicates use of GABA; blue indicates use of dopamine.

Abbreviations: GPe (external aspect of the globus pallidus); GPi (internal aspect of the globus pallidus); STN (sub-thalamic nucleus); SNpr (substantia nigra pars reticulata); SNpc (substantia nigra pars compacta). (For interpretation of the references to colour in this figure legend, the reader is referred to the web version of the article.) 